ARTÍCULOS 



\title{
El tópico del burlador-burlado en los Caballeros de Aristófanes
}

\author{
María Jimena SCHERE \\ Universidad de Buenos Aires \\ jimenaschere@hotmail.com
}

RESUMEN: El tópico del burlador-burlado se construye al rededor de un personaje negativo que practica el engaño, pero que termina vencido por otro personaje positivo que lo supera en astucia y en calidad moral. La comedia Caballeros adopta el tópico tradicional, presente en géneros como la épica, la fábula y el yambo, y lo utiliza en forma estratégica para degradar la imagen pública del líder político más destacado de su época, el demagogo Cleón. Al utilizar este tópico, los valores negativos del motivo recaen sobre la figura del líder con el aval de una larga tradición literaria.

\section{The Deceived Deceiver's Motif in Aristophanes' Knights}

ABSTRACT: The deceived deceiver's motif is developed around a negative character who exploits deception. However, he is eventually overcome by a positive character surpassing him in cleverness and moral quality. In his Knights, Aristophanes takes up the traditional motif, which is known from genres such as epic, fable, and iambic poetry, and uses it strategically to debase the public image of the most prominent leader of the time, the demagogue Cleon. Through the use of this motif, its negative traits are projected upon the leader's figure with the support of a long literary tradition.

PALABRAS ClaVE: Tópico, burlador-burlado, estrategia argumentativa, tradición literaria, Cleón.

KEYWORDS: Topic, deceived deceiver, argumentative strategy, literary tradition, Cleon.

FECHA DE RECEPCIÓN: 8 de febrero de 2012.

FECHA DE ACEPTACIÓN: 20 de agosto de 2012. 



\title{
El tópico del burlador-burlado en los Caballeros de Aristófanes
}

\author{
María Jimena SCHERE
}

\section{El tópico del burlador-burlado en la tradición literaria griega}

La comedia Caballeros de Aristófanes pone en escena una sátira virulenta contra el líder político Cleón, quien contaba con la máxima influencia sobre el dêmos votante hacia el momento de la representación de la obra (424 a. C.). ${ }^{1}$ Caballeros implementa una serie de estrategias argumentativas con la finalidad de que el ataque contra Cleón alcance su máxima eficacia. A nuestro modo de ver, el uso de tópicos cómicos, heredados de la tradición literaria, cumple una función fundamental en el marco de esta estrategia persuasiva que tiene el objetivo de degradar al demagogo a los ojos del público. En este trabajo nos proponemos, en primer lugar, realizar un breve rastreo del tópico del burlador-burlado en géneros que anteceden a la comedia: la épica, la fábula y el yambo; luego analizaremos el uso argumentativo de este tópos tradicional en la comedia Caballeros.

El motivo del burlador-burlado involucra la presencia de dos personajes antagonistas: en primer lugar, la figura de un héroe astuto y victorioso; en segundo orden, la figura negativa del burlador-burlado, quien intenta engañar al héroe, pero termina vencido por la inteligencia superior de su oponente.

En los estudios folclóricos, el motivo del burlador-burlado ha sido vinculado con la figura del trickster. En su influyente libro sobre el tema, Radin (1956) sostiene que el trickster no sólo engaña, sino que resulta a su vez engañado: "he who dupes others and who is always duped himself". ${ }^{2} \mathrm{Ra}-$ din caracteriza al trickster como un personaje que representa la mentalidad humana en un pasado primordial, obsesionada por el deseo sexual, la voracidad sin límites y el deseo de deambular. ${ }^{3}$

${ }^{1}$ El historiador Tucídides destaca que Cleón "era por ese entonces el orador de máxima influencia sobre el dêmos" (Th., III, 36, 6, cf. Th., IV, 21, 3).

${ }^{2}$ Radin, 1972, p. xxiii. Cf. Koepping, 1985, p. 206.

${ }^{3}$ Radin, 1972, pp. 167-168. 
Más allá de los rasgos comunes de la figura del trickster en distintas sociedades, es importante observar las particularidades de cada uso en las distintas culturas y géneros, y evitar caer en los excesos de los estudios comparativos. ${ }^{4}$ En la literatura griega, el personaje del trickster aparece realzado por el valor que se atribuye a la astucia en la cultura griega. Como bien observan Hynes y Doty (1993): "para los griegos la habilidad del engaño (trickery) era parte del ideal para alcanzar el éxito masculino en la guerra, en los asuntos amorosos y el comercio".

En la Odisea de Homero, el héroe del poema se ajusta a la figura folclórica del trickster en tanto que posee astucia ( $\mu$ îtı) y capacidad de engaño

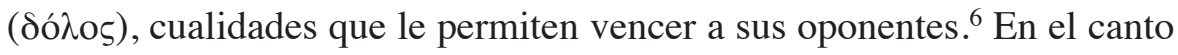
IX, por ejemplo, que presenta el enfrentamiento entre el héroe y el Cíclope, Odiseo resulta el burlador y el vencedor de Polifemo, ${ }^{7}$ personaje que encarna el estereotipo del tonto burlado. Si bien el Cíclope sobrepasa claramente a Odiseo en fuerza bruta, el héroe lo supera en perspicacia. ${ }^{8}$

En el canto IX de la Odisea también hay un breve episodio en donde el Cíclope intenta burlar a su vez a su antagonista (vv. 279-283); sin embargo, su iniciativa no tiene ningún éxito. En esta escena, el Cíclope, antes de revelar su intención de devorar a Odiseo y a sus hombres, trata de averiguar dónde han dejado su nave, a fin de asegurarse de que sus víctimas no puedan escapar ilesas de su tierra. Sin embargo, el astuto Odiseo no cae en la trampa y engaña a Polifemo con un dato falso:

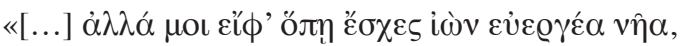

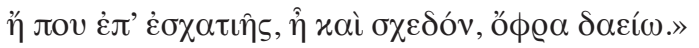

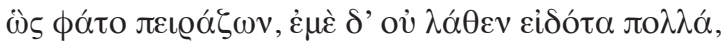

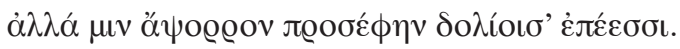

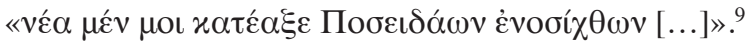

“[...] Dime para que lo sepa, ¿ dónde dejaste al venir la bien construida nave, en un lugar apartado o cerca?"

${ }^{4}$ Cf. Grottanelli, 1983, pp. 118-119; cf. Radin, 1972, p. xxiv.

${ }^{5}$ Hynes y Doty, 1993, p. 28.

${ }^{6}$ Cook (2009) ha analizado la figura de Odiseo en su condición de trickster.

${ }^{7}$ Ricketts (1966, pp. 343 y 346) observa que el trickster siempre resulta vencedor.

${ }^{8}$ Grotanelli (1983, p. 120) destaca que el poder del trickster es su inteligencia.

${ }^{9}$ Utilizamos la edición de Murray, 1919. Las traducciones de todos los textos griegos son propias. 
Así dijo [el Cíclope] probándome, pero a mí, conocedor de muchas cosas, no [me pasó inadvertido, sino que contesté de nuevo con palabras engañosas:

"Poseidón que sacude la tierra estrelló mi nave [...]".

Este pasaje contiene un germen del esquema tópico del burlador-burlado: el Cíclope intenta sojuzgar y burlar a Odiseo, subestimando su inteligencia, pero este último se impone como burlador definitivo de su ingenuo antagonista. También el desenlace del episodio consagra la victoria del héroe y destaca su superioridad respecto de su enemigo: Polifemo termina por perder su único ojo, derrotado por la audacia y el ingenio de Odiseo, quien se ríe de la inocencia de su salvaje adversario (vv. 413-414). Polifemo, en su condición de burlador-burlado, se caracteriza por ser inferior al héroe en dos planos a la vez: en astucia y en calidad moral. Esta disimetría entre los dos personajes involucrados en el tópico constituye un rasgo convencional del motivo que se reitera en otros géneros de la literatura griega.

Podemos observar que, si bien desde los estudios folclóricos se ha señalado que el trickster puede resultar también un burlador-burlado, ${ }^{10}$ en el canto IX de la Odisea los roles aparecen diferenciados con claridad. Odiseo representa la figura de un trickster positivo, heroico, astuto, vencedor y destructor de monstruos, mientras que el Cíclope constituye el polo opuesto del tonto vencido, la figura del víльos ("niño", "ingenuo", "tonto"), como lo llama Odiseo en el v. 442. Se desprende de este pasaje que cuando el víлıоs pretende burlar al héroe e incursionar en el terreno del astuto, no logra alcanzar el éxito y se convierte en un ingenuo burlador, burlado por la inteligencia superior del héroe. Odiseo, en cambio, consigue siempre salir airoso gracias a sus estratagemas. Evidentemente, Odiseo encarna los valores positivos de la obra: la astucia vencedora y la civilización versus la estupidez y el salvajismo del Cíclope. En este sentido, coincidimos con Ricketts (1966) en destacar la condición del trickster como héroe de la cultura. Ricketts ha cuestionado a Radin por separar el ciclo del trickster del ciclo heroico ${ }^{11}$ y ha observado que el trickster, además de sus rasgos bajos, su condición amoral y sus apetitos incontrolables, es también un héroe de la cultura y un transformador del

\footnotetext{
${ }^{10}$ Cf. n. 2.

${ }^{11}$ Radin, 1972, pp. 167-168.
} 
mundo. ${ }^{12}$ No se trata de un héroe ideal, sino de un héroe muy humano, que utiliza el engaño para vencer a personajes superiores. ${ }^{13}$ A nuestro modo de ver, la condición del trickster Odiseo como héroe de la cultura, destructor de monstruos, le aporta al personaje un sesgo positivo, que será heredado en la comedia por la figura del héroe cómico (i. e. Diceópolis, Morcillero, Trigeo, etc.). Estos héroes humanos, nunca ideales, resultan ser los burladores y vencedores definitivos de sus poderosos rivales (i. e. Lámaco, Paflagonio, Pólemos), partidarios de la guerra y de las prácticas políticas deshonestas. Por su parte, la figura del burlador-burlado adopta en la Odisea una imagen claramente devaluada, como representante del salvajismo anómico y la falta de capacidad y de astucia verdadera, visión negativa que se mantiene en otros géneros de la literatura griega, según intentaremos demostrar.

También en la fábula es posible detectar de manera clara la presencia del tópico con sus características convencionales. El género fabulístico griego, que celebra los valores aristocráticos de la fuerza y de la astucia, suele ubicar como blanco cómico central, burlado y aleccionado, a aquel personaje que resulta ser inferior en inteligencia. Un buen ejemplo del uso del tópico del burlador-burlado aparece en la fábula "La comadreja y las gallinas":

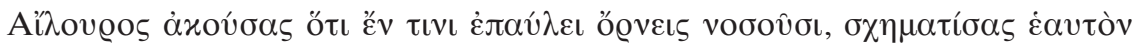

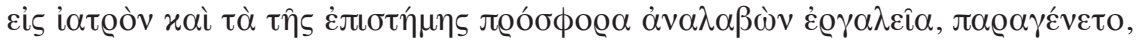

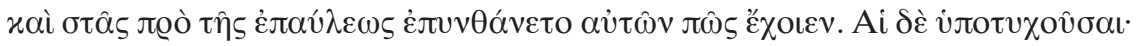

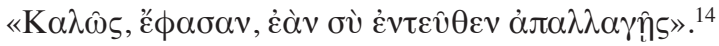

Una comadreja, luego de haber oído que en una granja las gallinas estaban enfermas, disfrazándose de médico y tomando los instrumentos necesarios de esta ciencia, se presentó y, deteniéndose ante la granja, les preguntó cómo estaban. Y ellas respondieron: "Bien, si tú te marchas de aquí".

En esta fábula, la comadreja intenta engañar a las gallinas adoptando una falsa identidad, pero ellas descubren la farsa y se burlan a su vez de

${ }^{12}$ Ricketts, 1966, p. 334. Otros autores han destacado también el carácter ambiguo y paradojal del trickster, que conjuga rasgos bajos con su condición de héroe de la cultura. Entre ellos, podemos mencionar a Grottanelli, 1983; Carroll, 1984; Koepping, 1985; Uther, 2006.

${ }^{13}$ Ricketts, 1966, pp. 334-336.

${ }^{14}$ Aesop., Fab., 14. 
su oponente con su comentario final. La comadreja asume entonces el papel de burladora-burlada, superada por la perspicacia de sus antagonistas. Como en la escena de la Odisea, la comadreja subestima a sus posibles víctimas, pero ella misma termina siendo objeto de la burla.

Otro ejemplo ilustrativo lo constituye "La zorra y el mono discuten por su prosapia" (Aesop., Fab., 39). El mono, al pasar por un cementerio, se jacta del linaje de sus antepasados. Sin embargo, la zorra advierte su engaño y deja su fanfarronería al descubierto mediante un comentario burlón, que cierra cómicamente la fábula:

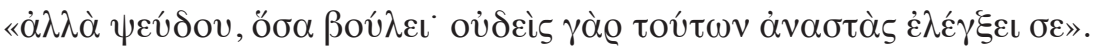

"Pues miente cuanto quieras, porque ninguno de ellos va a levantarse para desmentirte".

En este caso, el engañador (el mono) resulta a su vez burlado por la zorra, que desenmascara sus mentiras mediante una expresión ingeniosa. ${ }^{15}$ En la fábula, al igual que en su antecedente homérico, el burlador-burlado recibe su escarnio a manos de su oponente, quien deja a la vista su inferioridad en el plano de la inteligencia. La figura del burlador adquiere un carácter positivo en la fábula, teniendo en cuenta el valor que la ideología aristocrática atribuye a la astucia. La fábula, como bien han observado Rodríguez Adrados y García Gual, celebra los valores aristocráticos de la fuerza y de la astucia. ${ }^{16}$ En este sentido, podemos afirmar que la figura del burlador y vencedor en la fábula, así como en la épica, se destaca positivamente sobre la imagen del burlador-burlado, que deja finalmente al descubierto su falta de verdadera perspicacia. Sin embargo, es importante resaltar una diferencia notable con el modelo épico: en la épica, la dupla antagonista tiene un carácter mítico y legendario, mientras que los personajes de la fábula encarnan al "hombre común", ${ }^{17}$ representados de

${ }^{15}$ La zorra, como afirma Rodríguez Adrados (1979, p. 172), “domina la fábula” y se caracteriza generalmente por ser "astuta, prudente y taimada". Uther (2006, p. 145), por su parte, señala que en el folclore la figura del zorro representa tanto valores positivos como negativos. El autor observa, sin embargo, que las astucias del zorro suelen presentarse bajo un enfoque que genera simpatía en el receptor.

${ }^{16}$ Cf. Rodríguez Adrados, 1979, p. 199; García Gual, 1977 y 1978, pp. 14-16.

${ }^{17}$ Stierle (1989) señala que los personajes de la fábula no aparecen individualizados porque representan a cualquier individuo, al hombre común; un mono y una zorra son 
acuerdo con las convenciones del género fabulístico a través de la figura de animales. En suma, el burlador-burlado ya no es un ser fantástico como el Cíclope, ni el trickster-burlador alcanza la estatura legendaria del héroe Odiseo. La fábula, entonces, desprende el tópico del espacio mitológico y lo lleva al ámbito mundano de la vida cotidiana, el mismo ámbito en el que suele desarrollarse la acción de la comedia antigua.

Este esquema tradicional es retomado por otro género, el yambo, antecesor de la comedia. ${ }^{18}$ Los poetas yámbicos han utilizado la fábula como recurso argumentativo-polémico para embestir contra su enemigo personal. ${ }^{19}$ A partir del empleo de la fábula, el yambo incorpora y resignifica el tópico del burlador-burlado. El epodo VII de Arquílo (cf. Rodríguez Adrados, 1981, pp. 213-220) cohace referencia a la historia de la zorra y el mono que discutían por la prosapia de este último, cuyo argumento conocemos a través de la citada fábula de Esopo (Fab., 39): ${ }^{20}$

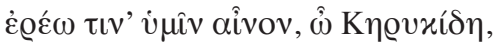

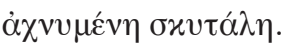

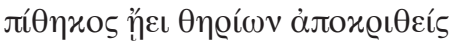

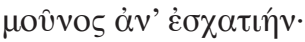

cualquier hombre. Sus breves historias tienen la función de representar una máxima de manera popular y accesible para todos. Por su parte, Rodríguez Adrados (1979, p. 172) destaca que la fábula va dirigida al hombre corriente de las clases inferiores. En este sentido, podemos sostener que la dupla tópica del héroe-burlador y de su antagonista, el burlador-burlado, deja el mundo legendario para descender al ámbito mundano del hombre común.

${ }^{18}$ Ya en la Antigüedad clásica, Aristóteles establece la vinculación entre poesía yámbica y comedia (Po., 1448b, 27; 1449a, 3; 1449b, 8). Sobre la relación entre estos géneros, véanse West, 1974, p. 37; Nagy, 1979, pp. 249-252; Rosen, 1988; Degani, 1991; Casadio, 1994; Zanetto, 2001; Cottone, 2005, pp. 143-170. Rosen, por ejemplo, argumenta que, desde Cratino, los poetas cómicos eran conscientes de la herencia yámbica y construían sus ataques de acuerdo con las convenciones genéricas heredadas. Degani concuerda con Rosen en que los poetas de la comedia antigua no ignoraban la procedencia yámbica de muchos de sus recursos. Por su parte, Rotstein alega que Aristóteles no establece una vinculación genealógica entre los dos géneros, sino una afinidad conceptual.

${ }^{19}$ Sobre la vinculación entre yambo y fábula, véanse Rodríguez Adrados, 1979, pp. 253-299; Lasserre, 1984; Carey, 1986, 2009; Rosen, 1988, pp. 31-33; van Dijk, 1997; Irwin, 1998; Zaneto 2001.

${ }^{20}$ Es preciso observar que la tradición atribuye a Esopo fábulas anteriores y posteriores a él que ya están presentes en Arquíloco. Al respecto, véase Chambry, 1927, p. xxix. 


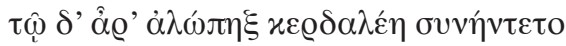

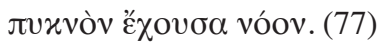

ótนعvov oîtov (78)

Ка@та́ $\theta \iota$

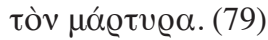

Os voy a contar una fábula, oh Querícidas,

triste escítala.

Un mono, separándose de los animales, se dirigió

a un lugar apartado.

Le salió al encuentro la astuta zorra

que tenía sagaz intención.

...un destino de esclavo...

Un carpatio [se buscó]

un testigo.

Según la reconstrucción de Rodríguez Adrados (1981), el mono pasa por un cementerio y llora ante la zorra por los antepasados de su familia, esclavos y libertos (fr. 77, 78), hecho que probaría la riqueza y antigüedad de su linaje. Pero la zorra deja su engaño al descubierto y se burla de él, aludiendo

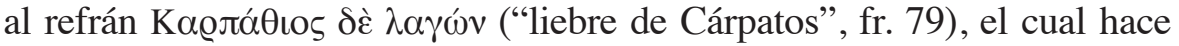
referencia a la historia de los habitantes de la isla de Cárpatos, quienes trajeron liebres del continente porque carecían de ellas en la isla, pero éstas devoraron sus cosechas. La burla de la zorra implicaría, entonces, que el mono se procuró mediante una mentira una prosapia ilustre que no tenía, pero que no le sirvió de nada porque ella no le creyó en absoluto. En este epodo, la zorra astuta se identificaría con la propia figura del "yo lírico", mientras que el mono burlado representa al adversario del poeta.

Otro claro ejemplo del tópico se puede detectar en el epodo IV (Rodríguez Adrados 1981, pp. 206-212), que incorpora la fábula del león viejo y la zorra: ${ }^{21}$

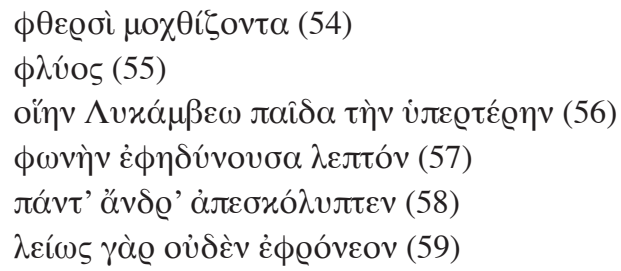

${ }^{21}$ Cf. Aesop., Fab., 196. 
...atormentado por los piojos...

...charla...

...como la hija mayor de Licambes...

...con una voz dulce y aguda...

...desollaba a cualquier hombre.

...pues no tenían absolutamente ninguna sensatez.

De acuerdo con la interpretación de Rodríguez Adrados, el león viejo, incapaz de procurarse alimento, invita a los animales a su cueva para charlar (fr. 55); pero cuando los incautos animales entran a la cueva, el león los devora. Al acercarse la zorra, el león le pregunta por qué no entra; ella le contesta que no lo hace porque puede ver las huellas de los animales que entraron, pero no de los que salieron. En el epodo el león es Neóbula, la hija de Licambes, el enemigo principal de Arquíloco, que habría faltado al juramento de entregarle a su hija por esposa. ${ }^{22}$ Neóbula, ya envejecida, se ha prostituido (fr. 58) e intenta atraer a Arquíloco (fr. 56, 57); pero el avisado poeta, al igual que la zorra astuta, no cae en su trampa como los demás animales (fr. 59). En este caso, la burladora de animales, Neóbula, resulta a su vez burlada por su antagonista, el poeta, que desbarata las intenciones de su oponente. En definitiva, el poeta se identifica con el animal positivo de la fábula, el trickster burlador y vencedor definitivo, y asocia a su enemigo con el animal negativo, el burlador-burlado, en este caso su enemigo personal y su hija Neóbula, que han violado los juramentos, pero que terminan ajusticiados por la poesía vengadora de Arquíloco. ${ }^{23}$

En conclusión, en los tres géneros citados (épica, fábula y yambo) encontramos un registro del tópico, que repite ciertos rasgos convencionales: el burlador-burlado intenta engañar y sobrepasar al héroe, pero termina vencido por su oponente, superior al primero en inteligencia y en calidad moral. En los tres casos, además, el motivo se emplea para devaluar a los ojos del receptor la figura negativa del antagonista y, conjuntamente, los valores que representa: el Cíclope simboliza el salvajismo y la anomia; el personaje aleccionado de la fábula encarna la bajeza moral y la falta de inteligencia;

${ }^{22}$ El enemigo principal ( $\left.\dot{\chi} \chi \emptyset \varrho o ́ \varsigma\right)$ contra el que Arquíloco dirige sus poemas es Licambes; su público está conformado por un grupo receptivo de amigos ( $\phi i ́ \lambda o \iota)$. Cf. Nagy, 1979, pp. 243-245.

${ }^{23}$ El poeta Arquíloco después de su muerte recibió en Paros culto como héroe (Rodríguez Adrados, 1981, p. 20). Esto demuestra que su figura, a pesar de sus rasgos controversiales (i. e. arrojar el escudo), pasa a la tradición con un sesgo heroico positivo. 
el enemigo del "yo lírico" representa el engaño y la violación de los juramentos. La actitud de estas figuras es presentada siempre bajo una óptica negativa, mientras que el personaje vencedor (i. e. Odiseo, el animal astuto, el poeta) actúa como un héroe justiciero que viene a desenmascarar, escarnecer y derrotar a su antagonista.

\section{El tópico del burlador-burlado en la comedia Caballeros}

La comedia Caballeros pone en escena el enfrentamiento entre el héroe cómico, el Morcillero, y su antagonista, Paflagonio, quien representa al líder político Cleón, blanco principal de la obra. Estos dos personajes centrales rivalizan por ganar el favor del pueblo y convertirse en su líder. Al comienzo de la pieza tanto el héroe como su oponente presentan rasgos negativos y ambos encarnan la figura del político nuevo, que se caracterizaba por provenir de familias no aristocráticas, a diferencia de los líderes tradicionales al estilo de Pericles. ${ }^{24}$ Paflagonio-Cleón se retrata como un demagogo venal y corrupto, que engaña al pueblo ateniense, personificado a través de la figura de Demos. ${ }^{25}$ En este sentido, Paflagonio opera como un burlador de Demos, a quien domina mediante la adulación y la concesión de aparentes beneficios. La relación entre Demos y su líder Paflagonio-Cleón se explicita por primera vez en el prólogo de la comedia por boca del esclavo Demóstenes (vv. 40-64). ${ }^{26}$

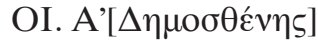

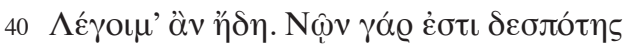

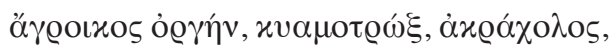

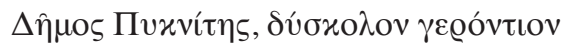

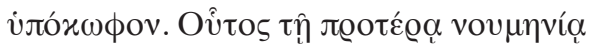

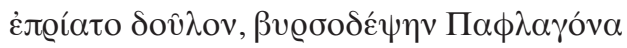

\footnotetext{
${ }^{24}$ Sobre los políticos nuevos, cf. Connor, 1992.

25 Traducimos el nombre del personaje como "Demos" en lugar de "Demo" para mantener el juego de palabras con el sustantivo común dêmos ("pueblo").

${ }^{26}$ Según los manuscritos medievales, los dos esclavos que inauguran la comedia representan a Nicias y Demóstenes. Sommerstein (1981, pp. 144-145) acepta la identidad de los dos esclavos. Por su parte, Dover (1959) afirma que la identidad del esclavo Demóstenes está confirmada por la referencia al suceso de Pilos (vv. 54-57), campaña en la cual éste participó junto con Cleón. Por el contrario, Henderson ([1998] 2006, p. 222) manifiesta que los dos esclavos son personajes genéricos. Cf. Henderson, 2003.
} 


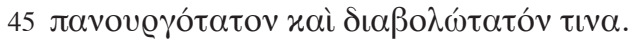

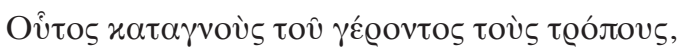

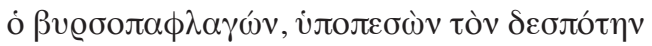

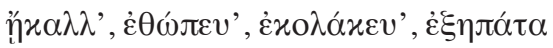

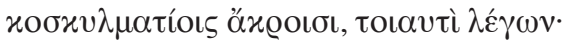

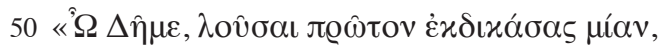

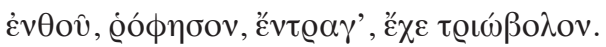

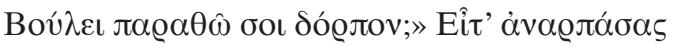

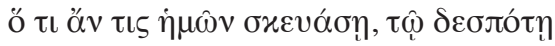

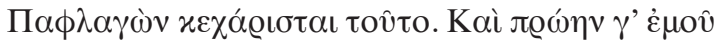

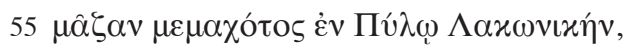

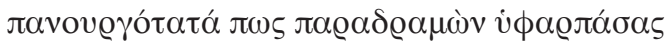

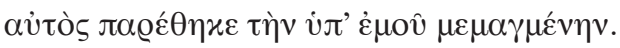

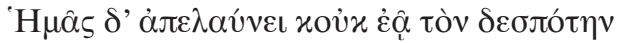

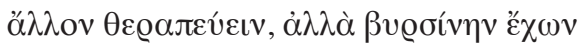

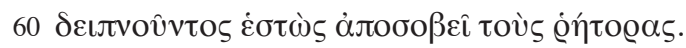

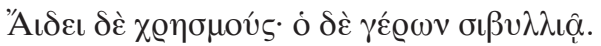

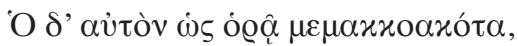

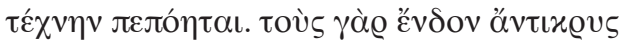

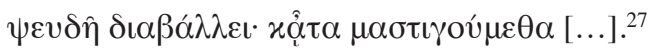

Esclavo A [Demóstenes]:

Ahora voy a hablar. Tenemos un señor

con ánimo de campesino, dado a comer habas, propenso a la cólera,

Demos de Pnyx, un viejito malhumorado,

un poco sordo. La luna nueva pasada

compró un esclavo, al curtidor de cueros Paflagonio,

alguien malvado al extremo y el más calumniador.

Este, al advertir el modo de ser del viejo,

el curtidor-de-pieles-Paflagonio, luego de echarse a los pies del señor,

lo halagaba, lo adulaba, lo lisonjeaba, lo engañaba

con la punta de los recortes del cuero diciendo estas cosas:

"Demos, date primero un baño, después de haber juzgado un solo pleito",

"Pon en tu boca, engulle, come el postre, ten el trióbolo",

“QQuieres que te sirva un refrigerio?” Luego, arrebatando

lo que cualquiera de nosotros preparó,

Paflagonio se lo ofrece al señor como regalo. Y el otro día,

${ }^{27}$ Utilizamos la edición de Sommerstein, 1981. 
cuando yo había amasado una torta lacónica en Pilos, con la mayor maldad, apresurándose, me la robó y le sirvió él mismo la torta que yo había amasado. A nosotros nos aparta y no permite que ningún otro se ocupe del señor, sino que con un matamoscas de cuero, mientras éste cena, de pie, espanta a los oradores. Y canta los oráculos; y el viejo cae en el delirio de la Sibila. Y cuando lo ve estupidizado, hace uso de su arte. Pues abiertamente contra los de la casa lanza mentiras. Y después nosotros somos azotados [...].

Esta primera descripción del personaje Paflagonio por parte de Demóstenes destaca la práctica permanente del engaño que el líder utiliza para dominar a Demos. La falsa adulación del pueblo (v. 48), la usurpación de méritos ajenos (i. e. el éxito de la campaña de Pilos, vv. 52-57) ${ }^{28}$ y la calumnia de otros oradores (v. 64) se presentan como los métodos de los que se vale Cleón para ocupar un lugar de privilegio en la asamblea ciudadana. También la concesión de aparentes beneficios al dêmos, como el aumento del salario de los jueces (v. 51), ${ }^{29}$ es parte de la estrategia engañosa y manipuladora del líder para conservar su poder. Paflagonio representa, en suma, la figura del burlador y engañador de Demos, que será finalmente descubierto por un burlador más astuto que él, su rival, el Morcillero.

${ }^{28}$ Caballeros denuncia que el éxito de la campaña de Pilos era atribuible al general Demóstenes. Véase Th., IV, 1-41. El episodio de Pilos, de acuerdo con el relato de Tucídides, se resume en los siguientes hechos: Demóstenes realiza un bloqueo a la isla de Pilos. Los peloponesios intentan firmar una tregua para que liberen a los prisioneros espartanos de la isla, pero Cleón promueve su rechazo. El bloqueo se prolonga de manera indefinida sin que se encuentre una solución definitiva al conflicto; cuando se acerca el invierno, los atenienses temen no poder aprovisionar a sus tropas y perder el control de Pilos. En ese momento, se escuchan en la asamblea murmuraciones contra Cleón por haber propulsado el rechazo de la tregua. Cleón, por su parte, critica a los generales responsables, en particular a Nicias, y se jacta de que si él mismo tuviera el mando podría vencer a los espartanos que habitaban en la isla y obtener el domino completo de Pilos. Los asistentes a la asamblea le toman la palabra y el demagogo no tiene otra alternativa que hacerse cargo de las operaciones. Finalmente, Cleón marcha a Pilos y, junto con el general Demóstenes, responsable del plan táctico, logra dominar a los espartanos que habían sobrevivido en la isla. Desde ese momento, Cleón conquista enorme fama en Atenas y recibe el derecho de ser alimentado en el Pritaneo a expensas del Estado.

${ }^{29}$ El salario que recibían los jueces por su actividad había sido aumentado a tres óbolos por iniciativa de Cleón. Cf. Sommerstein, 1981, p. 147. 
La caracterización de Paflagonio como farsante y burlador de Demos se retoma en la obra de manera constante: por ejemplo, en los versos 801-809 la práctica del engaño y la concesión de falsos beneficios para el pueblo es denunciada abiertamente por el Morcillero, que encarna su papel convencional de justiciero:
$\mathrm{A} \Lambda \Lambda \mathrm{ANTO \Pi \Omega \Lambda H \Sigma} \cdot$

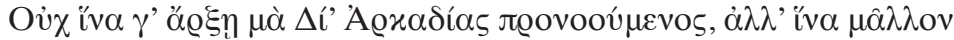

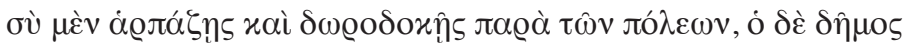

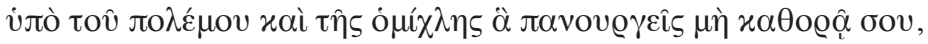

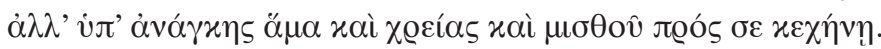

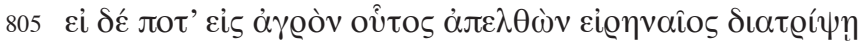

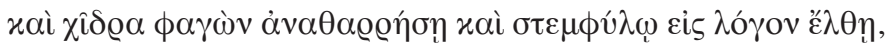

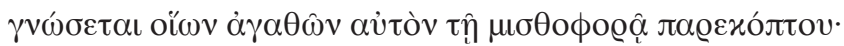

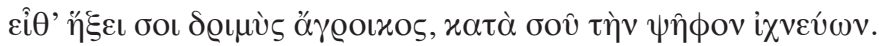

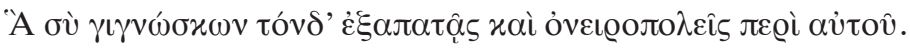

\section{MORCILLERO:}

¡Por Zeus! No te preocupas de que [Demos] tenga el poder en la Arcadia,

[sino más bien

de robar y recibir sobornos de las ciudades, y de que el dêmos a causa de la guerra y la nube de polvo no vea los males que haces, sino que se quede boquiabierto ante ti por obligación, por la necesidad

Pero si alguna vez, habiendo vuelto al campo, vive en paz

[y por el salario.

y recobra el ánimo comiendo cebada verde y entra en tratos con el olivo [prensado, reconocerá qué bienes le quitabas por medio de engaños con el salario. Entonces vendrá contra ti, como fiero campesino, buscando el voto para [condenarte.

Como sabes estas cosas, lo engañas y lo haces soñar.

En este pasaje, el Morcillero denuncia de manera explícita los engaños (v. 809) de Paflagonio: el líder pugna por la continuidad de la guerra del Peloponeso para que el pueblo campesino, alejado de sus tierras, se vea obligado a vivir en la ciudad y dependa del salario público que cobraba por su actividad de juez. ${ }^{30}$ Paflagonio conforma al pueblo con la falsa pre-

${ }^{30}$ Cf. n. 29. 
rrogativa de aumentar sus salarios, tema recurrente en la obra (cf. v. 51), al tiempo que roba y saca partido económico de la guerra. El Morcillero, por su parte, asume el lugar de burlador y vencedor final de Paflagonio al desenmascarar los engaños del primero. Si en el parlamento del esclavo Demóstenes, antes citado, los métodos de Cleón se denuncian para el público espectador en ausencia de Demos, en este caso el propio personaje de Demos, alter ego en escena del público demótico, constituye el destinatario del discurso.

Las revelaciones del Morcillero ante Demos alcanzan su punto culminante en las escenas finales cuando éste propone que Demos revise la cesta de ambos rivales para determinar cuál de los dos resulta un mejor líder para el pueblo (vv. 1211-13). Demos comprueba que la canasta del Morcillero está vacía, pero que Paflagonio se ha guardado algunas cosas (vv. 1214-20).

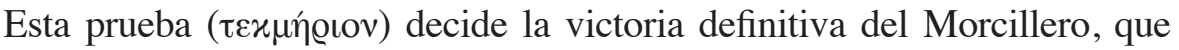
toma la corona en lugar de Paflagonio (vv. 1227-8). La escena de la canasta retoma la imagen recurrente de Paflagonio como un ladrón de los fondos públicos, como un líder preocupado por cuidar sus propios intereses más que los del pueblo, ${ }^{31}$ y remite una vez más al tópico del burlador de Demos, burlado a su vez por la acción iluminadora del héroe.

$\mathrm{Si}$ al principio la imagen de los dos personajes rivales es igualmente negativa en ambos casos, el desenlace de la obra rescata la figura del Morcillero, que se transforma mágicamente en un buen líder y guía a Demos hacia su conversión definitiva y hacia el repudio de las políticas que ha avalado en el pasado a instancia de Paflagonio-Cleón (vv. 1316 ss.). Por cierto, el liderazgo del Morcillero promueve la adopción por parte de Demos de una serie de medidas políticas opuestas a la orientación de Cleón. El nuevo programa político de Demos apunta a asegurar el legítimo salario de los remeros (vv. 1366-7); prohíbe que los hoplitas, una vez enrolados, puedan cambiar de inscripción (vv. 1369-1371); por último, propone evitar la influencia de los jóvenes políticos adiestrados en el arte de la retórica (vv. 1373-1380). A partir de este cambio, podemos afirmar que, a pesar de la imagen negativa del Morcillero desde el comienzo de la pieza, el desenlace presenta una imagen renovada del personaje que destaca positivamente su liderazgo. Por su parte, Paflagonio termina derrota-

${ }^{31}$ Reckford (1987, p. 117) señala que la escena manifiesta la diferencia entre el Morcillero y Paflagonio; este último se encuentra más interesado en comer que en alimentar a Demos. Al respecto, véase también Wilkins, 2000, pp. 179-189. 
do y se convierte en un engañador vencido por la sagacidad y la condición moral superior del héroe.

Al igual que en los géneros antecesores, el tópico del burlador-burlado opera como un recurso que sirve para descalificar la figura del antagonista tanto desde el punto de vista moral como intelectual. La carga negativa del tópico heredado recae sobre Paflagonio-Cleón y ayuda a devaluar la imagen pública del líder con el aval de la tradición literaria. De este modo, los sentidos negativos asociados al tópico del burladorburlado se imprimen sobre este nuevo blanco de ataque generando un efecto argumentativo degradante. Mediante la utilización del tópico, el héroe cómico queda asociado a las figuras positivas de la épica, la fábula y el yambo (i. e. Odiseo, el animal astuto, el poeta yámbico), ${ }^{32}$ mientras que Paflagonio aparece vinculado con la imagen negativa del burlador-burlado tradicional.

La crítica ha planteado la aparente identidad entre los dos rivales de la obra. Beltrametti (2000), por ejemplo, ha sostenido que en el par cómico del Morcillero y Paflagonio no hay verdadera antinomia, sino un juego de espejos. ${ }^{33}$ Creemos que esta afirmación es parcialmente cierta, pero que no da cuenta de la verdadera complejidad del personaje. El Morcillero ocupa un lugar superior en tanto resulta ser finalmente el burlador definitivo de Paflagonio al dejar a la vista sus engaños. Su condición de burlador del burlador lo presenta bajo una mirada positiva de justiciero, que no es equivalente a la imagen irredimible de Paflagonio. ${ }^{34}$

${ }^{32}$ La crítica ha señalado que la figura de los héroes aristofánicos se construye con base en la presencia de un héroe astuto al estilo de Odiseo (cf. Whitman, 1964, p. 28; De Lamberterie, 1998, p. 33). Sin embargo, es preciso añadir que el héroe astuto, en el caso de Caballeros, se opone a la figura de otro personaje engañador, pero que termina superado por el héroe cómico.

${ }^{33}$ Beltrametti, 2000, p. 219.

${ }^{34}$ La crítica ha ensayado diferentes respuestas frente a la aparente inconsistencia y duplicidad negativa / positiva del Morcillero: algunos autores como Whitman (1964) han intentado resolver la complejidad del personaje a partir de la categoría de héroe cómico, quien reuniría a la vez rasgos animales, humanos y divinos; otros estudiosos, como Bennet y Blake Tyrrell (1990) y Bowie (1993) explican el carácter del personaje del Morcillero a partir de la ideología del fármaco: el Morcillero, sostienen, es un político amoral, diferente a Paflagonio en grado, pero no en sustancia. La inversión que sufre el Morcillero al final de la obra es igual a la que experimenta el fármaco: el individuo más repugnante puede curar a la ciudad de su enfermedad. Landfester (1967), por ejemplo, asume la hipótesis de que el Morcillero esconde en realidad una personalidad cuasidivina. 
Además de la clara transformación final del Morcillero, hay una serie de factores que permiten destacar positivamente su figura en comparación con la de Paflagonio. En la obra hay tres escenas agonales que significan un incremento gradual del poder del Morcillero y el debilitamiento de Paflagonio. ${ }^{35}$ La primera (vv. 235-497) se desarrolla entre los personajes que se oponen a Paflagonio-Cleón desde el comienzo de la pieza (Demóstenes, los caballeros y el Morcillero); la segunda se ubica en el Consejo (vv. 624-682), y la tercera, frente a Demos (vv. 691-1408). Las victorias sucesivas del Morcillero en los tres episodios agonales mencionados van legitimando progresivamente su imagen negativa del comienzo ante el público. En el tópico tradicional del trickster-burlador y del burlador-burlado, según observamos, también el primero sale siempre airoso. Esta misma condición victoriosa, reiterada y potenciada en la serie de agônes, ubica al Morcillero en un lugar destacado respecto al de su oponente, que se corona con su victoria final y definitiva. El Morcillero resulta ser el destructor heroico de monstruos, que derrota a su horrible rival Paflagonio, cuyo aspecto físico suele describirse como el de un hombre espantoso. ${ }^{36}$ Vale aclarar que la figura del héroe cómico aristofánico representa una forma particular de heroísmo propia del género. En la

Brock (1986) por su parte, justifica la doble cara del personaje a partir de la duplicidad entre una visión cínica y una idealista de la política ateniense: el autor observa que en las escenas de apertura se subraya la maldad y el bajo estatus del Morcillero y se deja entender que usará las mismas técnicas que Paflagonio. Desde una concepción cínica de la democracia ateniense, la salvación que promete la figura del Morcillero se limita a rescatar a los dos esclavos del poder de Paflagonio y sustituirlo por un demagogo aún peor, pero amigo. Sólo el final de la obra presenta una reforma idealista del Morcillero y de Demos, que representa una transformación completa de la política ateniense. Recientemente, Olson (2010) manifiesta que el Morcillero es peor que Paflagonio y que la situación de la democracia no tiene una salida positiva ni puede ser corregida. A nuestro modo de ver, el Morcillero y Paflagonio no son personajes equivalentes, sino que el primero se redime por burlar y desenmascarar al segundo.

${ }^{35}$ Whitman (1964, pp. 88-89) señala que toda la obra constituye un gran agón dividido en tres eventos principales. Brock (1986, pp. 25), entre otros autores, reafirma que la obra constituye una serie de agônes que representan las caídas sucesivas de Paflagonio

${ }^{36}$ En el pasaje 231-233, el esclavo Demóstenes señala que ningún fabricante de máscaras se ha atrevido a retratar al verdadera Cleón. A partir de este pasaje, Dover [1967] (1975) sostiene que la máscara del líder debería haber sido especialmente espantosa, acorde con la habitual representación monstruosa del demagogo (cf. Av., vv. 1031-1035; Pax, vv. 753-758). 
comedia temprana, suele adoptar los rasgos de un trickster muy humano, jamás idealizado ni carente de defectos, un Odiseo burlador ${ }^{37}$ que derrota a personajes superiores, y que suele ser el portavoz de la ideología sustentada en la pieza. Por ejemplo, Diceópolis y Trigeo, que se enfrentan respectivamente a los poderosos Lámaco y Pólemos, abogan en defensa de la Paz. Asimismo, en Caballeros, como observamos, el Morcillero al final de la obra guía a Demos hacia una política contraria a la cleoniana y derrota a su difícil contrincante. En el motivo folclórico del trickster, también esta figura conjuga rasgos bajos con su condición de héroe transformador y benéfico.

Otro factor que destaca al Morcillero respecto de su antagonista es el hecho de recibir elogios, raro privilegio en la comedia aristofánica. El

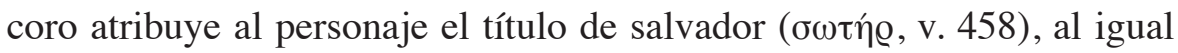
que otros héroes cómicos como Trigeo y Lisístrata. En definitiva, la figura elogiada, burladora y victoriosa del Morcillero alcanza en la obra finalmente un status claramente superior al de su antagonista Paflagonio, a pesar de la aparente identidad del comienzo.

La comedia Caballeros utiliza el motivo tradicional con fines argumentativos, pero introduce variantes respecto de sus modelos antecesores, que son acordes con las intenciones comunicativas de la pieza. En primer lugar, en la tradición la figura del burlador y la del burlador-burlado se presentan bajo la forma del binomio. También en Caballeros se mantiene la presencia de la dupla tópica del burlador y vencedor definitivo versus el burlador-burlado; sin embargo, se suma un tercer componente, el personaje de Demos, víctima del malvado Paflagonio. Mientras que el Morcillero jamás se deja burlar por su antagonista, Demos sufre los engaños de Paflagonio y sólo abandona su ingenuidad bajo la buena guía del héroe. La presencia del tercer componente no hace más que destacar la figura heroica del Morcillero que no sólo es un personaje astuto, incapaz de dejarse engañar por su oponente, sino que además logra hacer salir de la necedad a la ciudadanía ateniense. El Morcillero, en definitiva, es un héroe salvador, no de sí mismo, como ocurre en el ejemplo de la Odisea

\footnotetext{
${ }^{37}$ Mientras que la comedia rescata positivamente la figura del Odiseo homérico a través del personaje del héroe, en la tragedia del siglo $\mathrm{v}$ aparece, en cambio, una visión devaluada de Odiseo (cf. Filoctectes de Sófocles). A nuestro modo de ver, la comedia y la tragedia recrean la figura de Odiseo de manera diferente y con una distinta valoración en cada caso.
} 
o de la fábula, sino de un tercero más vulnerable, el influenciable Demos, incapaz de advertir por sí mismo los engaños de los demagogos.

También podemos subrayar algunas otras diferencias con el esquema tradicional. En Caballeros, el burlador-burlado ya no es un personaje fantástico que pertenece a un mundo mítico como el Cíclope, ni un animal que representa al hombre común de manera genérica como en la fábula. ${ }^{38}$ Por el contrario, el burlador-burlado de Caballeros es un líder de existencia real en el mundo de la política ateniense; por lo tanto, los efectos degradantes del tópico pueden devaluar su imagen pública de manera concreta y efectiva. En el yambo también el poeta utiliza el tópico del burlador-burlado para mofarse de sus enemigos personales, de existencia pretendidamente extratextual. Sin embargo, los blancos de ataque del yambo no tienen la relevancia pública ni política de una figura como Cleón, el demagogo más influyente de la época. En este sentido, el tópico adquiere en Caballeros una fuerza argumentativa degradante muy superior a sus modelos antecesores.

\section{Conclusiones}

El tópico del burlador-burlado, detectado en la épica, en la fábula, en el yambo y en la comedia, se caracteriza por presentar de manera negativa la figura de un personaje que practica el engaño, pero que termina vencido por un personaje positivo, un vengador justiciero, que lo descubre y que lo supera en el plano de la astucia y de la calidad moral. La comedia $\mathrm{Ca}$ balleros adopta el tópico heredado y lo utiliza en forma estratégica para degradar la imagen pública del líder contemporáneo más destacado de la época, el demagogo Cleón. El líder se presenta como el burlador de Demos, burlado a su vez por su rival heroico. Al emplear este tópico, los valores negativos del motivo recaen sobre la figura del líder y lo devalúan con el fuerte aval de la tradición literaria.

En los cuatro géneros analizados, el tópico se utiliza sin excepción para atacar al antagonista del héroe y, al mismo tiempo, a las ideas negativas que éste encarna: el salvajismo y la anomia del ingenuo Cíclope, la inferioridad moral e intelectual del animal aleccionado de la fábula, la violación de los juramentos perpetrada por el enemigo personal del poeta yámbico, la política deshonesta y nociva sustentada por Cleón. La apli-

\footnotetext{
${ }^{38}$ Cf. n. 17.
} 
cación del tópico sobre Paflagonio transfiere a su figura todas esas ideas negativas tradicionales: la falta de civilización, la anomia, la bajeza moral y la inferioridad intelectual. A esos valores cuestionados se suman además nuevos sesgos negativos acordes con el género de la comedia antigua: la corrupción, la demagogia, la tendencia a la difamación del líder político dominante del momento, conductas altamente nocivas para el conjunto, en tanto dañan al común de los ciudadanos de la pólis. Por otra parte, el burlador-burlado de la comedia, a diferencia de los modelos antecesores, posee una referencia concreta, individualizada y de alta relevancia política que no está presente en los modelos anteriores. En este sentido, la comedia aristofánica incrementa el potencial argumentativo-polémico del motivo, que puede afectar en este caso de manera efectiva la imagen pública de un individuo histórico poderoso e influyente en la Atenas de la época.

La aplicación del motivo tradicional en Caballeros contribuye a presentar bajo una óptica negativa los mayores éxitos políticos del Cleón histórico. Según hemos señalado, Cleón gozaba por el momento de la representación de la pieza de la máxima popularidad ante el dêmos, gracias a su reciente éxito militar en la campaña de Pilos; ${ }^{39}$ asimismo, su condición de líder político nuevo, carente de linaje aristocrático, y sus medidas tendientes a beneficiar al pueblo, como el aumento del salario de los jueces, le habían otorgado gran prestigio entre los sectores populares. Bajo la luz negativa del tópico, las medidas políticas y las acciones militares más celebradas de Cleón se convierten en burdas estrategias engañosas, fáciles de desenmascarar; es decir, el tipo de situaciones que caracterizan al burlador-burlado. Por ejemplo, el aumento del salario de los jueces se presenta como una obvia maniobra para comprar voluntades y preservar el poder del líder; el episodio de Pilos, glorioso para Cleón, se transforma en una falaz victoria que encubre el verdadero mérito de Demóstenes; de igual modo, la prolongación de la guerra del Peloponeso, propiciada por el líder, reviste el vil propósito de mantener al pueblo en condiciones paupérrimas, sometido al liderazgo de Cleón. En suma, la política cleoniana se presenta como un mero engaño, es deshonesta y no hace otra cosa que favorecer al propio líder y mantenerlo en su lugar de privilegio, pero resulta fácilmente desarticulable bajo la mirada sagaz del Morcillero.

${ }^{39}$ Sobre el episodio de Pilos, véase nota 28. 
En virtud de la popularidad del líder político, ubicar a Cleón como el eje de la sátira en Caballeros entrañaría el riesgo para el comediógrafo de perder la complicidad y la adhesión del público. En este sentido, el uso del tópico tradicional, que porta en sí mismo una carga negativa consensuada, habrá propiciado la generación de una complicidad necesaria entre el comediógrafo y su público. El tópico favorece la estrategia persuasiva de la pieza en tanto que imprime sobre la figura de Cleón una serie de sentidos negativos consensuados y presenta sus medidas más populares como burdos engaños al pueblo.

\section{BIBLIOGRAFÍA}

\section{Fuentes}

ARISTOPHANES, Comedies. Acharnians, vol. 1, edited and translated by J. Henderson, Cambridge / Massachusetts, Harvard University Press, 2006 [1998].

_, Comedies. Knights, vol. 2, edited by A. H. Sommerstein, Warminster, Aris \& Phillips, 1981.

ARISTOTELIS, De Arte Poetica liber, recognovit brevique adnotatione critica instruxit I. Bywater, Oxford, Oxford University Press, 1938 [1897] (Scriptorum Classicorum Bibliotheca Oxoniensis).

Ésope, Fables, texte établi et traduit par E. Chambry, Paris, Les Belles Lettres, 1927, (Collection des Universités de France).

Esopo. Fábulas. Babrio, Fábulas, traducción y notas de P. Bádenas de la Peña y J. López Facal, Madrid, Gredos, 1978.

Homer, The Odyssey, translation by A. T. Murray, London / Cambridge, William Heinemann / Harvard University Press, 1919 (Loeb Classical Library).

THUCYDIDIS, Historiae, recognovit et brevique adnotatione critica instruxit H. S. Jones, Oxford, Oxford University Press, 1958 [1900] (Scriptorum Classicorum Bibliotheca Oxiniensis).

\section{Estudios}

Beltrametti, A., "Le couple comique. Des origines mythiques aux dérives philosophiques", en M. L. Desclos (éd.), Le rire des Grecs. Anthropologie du rire en Grèce ancienne, Grenoble, Editons Jérome Million, 2000, pp. 215-226.

BennetT, L. J. \& W. M. Blake Tyrrell, "Making Sense of Aristophanes' Knights", Arethusa, 23, 2, 1990, pp. 235-252.

Brelich, A., "Aristofane, commedia e religione", en M. Detienne (ed.), Il mito. Guida storica e critica, Roma / Bari, Laterza, 1982 [1969], pp. 103-118.

BowIE, A. M., Aristophanes. Myth, Ritual and Comedy, Cambridge, Cambridge University Press, 1993.

Brock, R. W., "The Double Plot in Aristophanes' Knights", Greek, Roman and Byzantine Studies, 27, 1, 1986, pp. 15-27. 
Carroll, M. P., “The Trickster as Selfish-Buffon and Culture Hero”, Ethos, 12, 2 , 1984, pp. 105-131.

CAREY, Ch., "Archilochus and Lycambes", The Classical Quarterly, 36, 1, 1986, pp. 60-67.

_, "Iambos", en F. Budelmann (ed.), The Cambridge Companion to Greek Lyric, Cambridge, Cambridge University Press, 2009, pp. 149-167.

CAsadio, V., "Presenza dei Giambografi in Aristofane", Museum Criticum, 29, 1994, pp. 161-170.

Connor, W. R., The New Politicians of Fifth-Century Athens, Indianapolis / Cambridge, Hackett Publishing Company, 1992 [1971].

Cook, E., “'Active' and 'Passive' Heroics in the Odyssey”, en L. E. Doherty (ed.), Oxford Readings in Classical Studies. Homer's Odyssey, Oxford / New York, Oxford University Press, 2009.

Cottone, R. S., Aristofane e la poetica dell' ingiuria. Per una introduzione alla

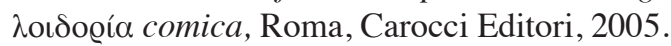

Degani, E., "Aristofane e la tradizione dell'invettiva personale in Grecia”, en J. M. Bremen \& E. W. Handley (éds.), Aristophane, Vandoeuvres / Genève, Fondation Hardt, 1991 (Entretiens sur L'Antiquité Classique, XXXVIII), pp. 1-49.

De Lamberterie, Ch., “Aristophane, lecteur d'Homère”, en M. Trédé et Ph. Hoffmann (éds.), Le rire des anciens. Actes du Colloque Internacional (Université de Rouen, École normale supérieure, 11-13 janvier 1995), Paris, Presses de l'École normale supérieure, 1998, pp. 33-52.

Dover, K. J., "Portrait-Masks in Aristophanes", en H. J. Newiger (Hrsg.), Aristophanes und die alte Komödie, Darmstadt, Wissenschaftliche Buchgessellschaft, 1975 [1967], pp. 155-169.

García GuAL, C., "La fábula esópica: estructura e ideología de un género popular", en Estudios ofrecidos a Emilio Alarcos Llorach, vol. 1, Oviedo, Universidad de Oviedo, 1977, pp. 309-322.

_, “Introducción”, en Fábulas y vida de Esopo. Fábulas de Babrio (traducción y notas de P. Bádenas de la Peña y J. López Facal), Madrid, Gredos, 1978.

Grottanelli, C., “Tricksters, Scapegoats, Champions, Saviors", History of Religions, 23, 1983, pp. 115-139.

Henderson, J., "When an Identity was expected: the Slaves in Aristophanes' Knights", en G. W. Bakewell \& J. P. Sickinger (eds.), Gestures. Essays in Ancient History, Literature, and Philosophy Presented to Alan L. Boegehold on the occasion of his retirement and his seventy-fifth birthday, Oxford, Oxbow Books, 2003, pp. 63-300.

Hynes, W. J.\& Doty, W. G, Mythical Trickster Figures. Contours, Contexts, and Criticisms, Tuscaloosa, University of Alabama Press, 1993.

IRwIN, E., "Biography, Fiction, and the Archilochean ainos", The Journal of Hellenic Studies, 118, 1998, pp. 177-183.

KoEPPING, K.-P., “Absurdity and Hidden Truth: Cunning Intelligence and Grotesque Body Images as Manifestations of the Trickster", History of Religions, 24, 1985 , pp. 191-214. 
LANDFESTER, M., Die Ritter des Aristophanes. Beobachtungen zur dramatischen Handlung und zum komischen Stil des Aristophanes, Amsterdam, B. R. Grüner, 1967. LASSERRE, F., "La fable en Grèce dans la poésie archaïque", en O. Reverdin et F. Rodríguez Adrados (éds.), La Fable, Vandoeuvres / Genève, Fondation Hardt, 1984 (Entretiens sur L'Antiquité Classique, XXX), pp. 61-103.

Nagy, G., The Best of the Achaeans. Conceps of the Hero in Archaic Greek Poetry, Baltimore / London, The Johns Hopkins University Press, 1979.

Olson, D. S., "Comedy, Politics, and Society", Brill's Companion to the Study of Greek Comedy, Leiden, Brill, 2010, pp. 35-69.

Radin, P., The Trickster. A Study in American Indian Mythology, New York, Schocken Books, 1972 [1956].

ReCKFord, K. J., Aristophanes' Old-and-New Comedy, Chapel Hill / London, University of North Carolina Press, 1987.

RicketTS, M. L., "The North American Indian Trickster", History of Religions, 5, 2 , 1966, pp. 327-350.

RODRíGUEZ ADRADOS, F., Historia de la fábula greco-latina, vol. 1: Introducción y de los orígenes a la edad helenística, Madrid, Editorial de la Universidad Complutense, 1979.

_, Líricos griegos. Elegíacos y yambógrafos arcaicos, Madrid, Consejo Superior de Investigaciones Científicas, 1981.

Rosen, R. M., Old Comedy and the Iambographic Tradition, Atlanta / Georgia, Scholars Press, 1988.

Rotstein, A., The Idea of Iambos, Oxford / New York, Oxford University Press, 2009.

STIERLE, K., "La historia como ejemplo, el ejemplo como historia", en E. Arnoux (ed.), Lingüística interdisciplinaria. El discurso histórico, Buenos Aires, Ediciones "Cursos Universitarios", 1989.

UtHeR, H.-J., "The Fox in World Literature: Reflections on a 'Fictional Animal", Asian Folklore Studies, 65, 2, 2006, pp. 133-160.

Van DiJK, G.-J., Ainoi, Logoi, Mythoi: Fables in Archaic, Classical, and Hellenistic Greek Literature, Leiden / New York / Köln, Brill, 1997.

West, M. L., Studies in Greek Elegy and Iambus, Berlin / New York, Walter de Gruyter, 1974 (Mnemosyne Supplementum, 166)

Whitman, C., Aristophanes and the Comic Hero, Cambridge / Massachusetts, Harvard University Press, 1964.

Wilkins, J., The Boastful Chef. The Discourse of Food in Ancient Greek Comedy, Oxford, Oxford University Press, 2000.

Zanetto, G., "Iambic Patterns in Aristophanic Comedy", en A. Cavarzere, A. Aloni \& A. Barchiesi (eds.), Iambic Ideas. Essays on a Poetic Tradition from Archaic Greece to the Late Roman Empire, Lanham / Boulder / New York / Oxford, Rowman \& Littlefield Publishers, 2001, pp. 65-76. 
